\title{
Face inversion disrupts the perception of vertical relations between features in the right human occipito- temporal cortex
}

Citation for published version (APA):

Goffaux, V., Rossion, B., Sorger, B., Schiltz, C., \& Goebel, R. (2009). Face inversion disrupts the perception of vertical relations between features in the right human occipito-temporal cortex. Journal of neuropsychology, 3(Pt 1), 45-67. https://doi.org/10.1348/174866408X292670

Document status and date:

Published: 01/01/2009

DOI:

10.1348/174866408X292670

Document Version:

Publisher's PDF, also known as Version of record

Document license:

Taverne

Please check the document version of this publication:

- A submitted manuscript is the version of the article upon submission and before peer-review. There can be important differences between the submitted version and the official published version of record.

People interested in the research are advised to contact the author for the final version of the publication, or visit the DOI to the publisher's website.

- The final author version and the galley proof are versions of the publication after peer review.

- The final published version features the final layout of the paper including the volume, issue and page numbers.

Link to publication

\footnotetext{
General rights rights.

- You may freely distribute the URL identifying the publication in the public portal. please follow below link for the End User Agreement:

www.umlib.nl/taverne-license

Take down policy

If you believe that this document breaches copyright please contact us at:

repository@maastrichtuniversity.nl

providing details and we will investigate your claim.
}

Copyright and moral rights for the publications made accessible in the public portal are retained by the authors and/or other copyright owners and it is a condition of accessing publications that users recognise and abide by the legal requirements associated with these

- Users may download and print one copy of any publication from the public portal for the purpose of private study or research.

- You may not further distribute the material or use it for any profit-making activity or commercial gain

If the publication is distributed under the terms of Article $25 \mathrm{fa}$ of the Dutch Copyright Act, indicated by the "Taverne" license above, 


\title{
Copyright (C) The British Psychological Society
}

Reproduction in any form (including the internet) is prohibited without prior permission from the Society

\section{Face inversion disrupts the perception of vertical relations between features in the right human occipito-temporal cortex}

\author{
Valerie Goffaux ${ }^{1,2 *}$, Bruno Rossion², Bettina Sorger', \\ Christine Schiltz ${ }^{2,3}$ and Rainer Goebel ${ }^{1}$ \\ 'Maastricht Brain Imaging Centre, University of Maastricht, Maastricht, \\ The Netherlands \\ ${ }^{2}$ Department of Cognitive Development, Université catholique de Louvain, \\ Louvain-la-Neuve, Belgium \\ ${ }^{3}$ Educational Measurements and Applied Cognitive Science Unit, \\ University of Luxembourg, Luxembourg
}

\begin{abstract}
The impact of inversion on the extraction of relational and featural face information was investigated in two fMRI experiments. Unlike previous studies, the contribution of horizontal and vertical spatial relations were considered separately since they have been shown to be differentially vulnerable to face inversion (Goffaux \& Rossion, 2007). Hence, inversion largely affects the perception of vertical relations (e.g. eye or mouth height) while the processing of features (e.g. eye shape and surface) and of horizontal relations (e.g. inter-ocular distance) is affected to a far lesser extent. Participants viewed pairs of faces that differed either at the level of one local feature (i.e. the eyes) or of the spatial relations of this feature with adjacent features. Changes of spatial relations were divided into two conditions, depending on the vertical or horizontal axis of the modifications. These stimulus conditions were presented in separate blocks in the first (block) experiment while they were presented in a random order in the second eventrelated (ER) experiment. Face-preferring voxels located in the right-lateralized middle fusiform gyrus (rMFG) largely decreased their activity with inversion. Inversion-related decreases were more moderate in left-lateralized middle fusiform gyrus (IMFG). ER experiment revealed that inversion affected rMFG and IMFG activity in distinct stimulus conditions. Whereas inversion affected IMFG processing only in featural condition, inversion selectively affected the processing of vertical relations in rMFG. Correlation analyses further indicated that the inversion effect (IE) observed in rMFG and right inferior occipital gyrus ( $\mathrm{IIOG)}$ reliably predicted the large behavioural IE observed for the processing of vertical relations. In contrast, IMFG IE correlated with the weak behavioural IE observed for the processing of horizontal relations. Our findings suggest
\end{abstract}

* Correspondence should be addressed to Dr Valerie Goffaux, Department of Neurocognition, Faculty of Psychology, University of Maastricht, Maastricht, 6200 MD, The Netherlands (e-mail: valerie.goffaux@psychology.unimaas.nl). 


\title{
Copyright (C) The British Psychological Society \\ Reproduction in any form (including the internet) is prohibited without prior permission from the Society
}

Valerie Goffaux et al.

\begin{abstract}
that face configuration is mostly encoded in rMFG, whereas more local aspects of face information, such as features and horizontal spatial relations drive IMFG processing. These findings corroborate the view that the vulnerability of face perception to inversion stems mainly from the disrupted processing of vertical face relations in the right-lateralized network of face-preferring regions ( $r M F G, r I O G$ ).
\end{abstract}

Human faces reveal peers' identity, intentions, emotional state, age, etc. This wealth of face information contributes to the regulation of social interactions. Accordingly, humans have developed highly skilled discrimination and recognition abilities for faces. The face processing system extracts the shape and surface properties of the features making up a face (eyes, nose, mouth, chin, eyebrows, etc.), but it is also sensitive to the spatial relations between features (e.g. distance between eyes or between nose and mouth). The joint processing of features and their spatial relations is usually coined 'configural' or 'holistic' processing (Rhodes, 1988; Sergent, 1984; Tanaka \& Farah, 1993). As illustrated by the well-known face 'composite' and 'Thatcher' illusions (see Maurer, Le Grand, \& Mondloch, 2002 for a review), configural/holistic processing implies that one can hardly access a unique facial feature without being influenced by other face features.

One of the most intriguing effects in face perception is its high vulnerability to inversion (first reported by Yin, 1969). Hence, merely turning a face upside-down impairs our ability to discriminate and recognize faces in a far larger extent than other visual stimuli such as car or dog pictures (Yin, 1969; see McKone, Kanwisher, \& Duchaine, 2007; Rossion \& Gauthier, 2002; Valentine, 1988 for reviews). Inversion affects the perceptual encoding of individual faces, as evidenced by simultaneous face matching experiments (e.g. Freire, Lee, \& Symons, 2000a) and event-related potential (ERP) studies with unfamiliar faces (see Jacques, d'Arripe, \& Rossion, 2007).

Several behavioural studies demonstrated that featural versus relational aspects of face information differentially suffer from inversion (e.g. Bartlett \& Searcy, 1993; Freire et al., 2000a). In these studies, featural processing is induced by manipulating the shape and/or surface of one or several features (e.g. eyes made darker and rounder or exchanged between individuals). Relational processing is targeted by displacing one or several features in a given face (e.g. increasing nose-mouth distance) while keeping their surface and shape properties constant. The largest face inversion effects (IE) are generally observed for relational processing, whereas featural processing is moderately affected (e.g. Bartlett \& Searcy, 1993; Freire et al., 2000a; Le Grand, Mondloch, Maurer, \& Brent, 2001). These findings support the view that features and their spatial relations are dissociable cues for face perception.

Recent fMRI studies investigated the neural basis of the face IE. Faces elicit a strong response bilaterally in occipito-temporal regions of the human brain, namely the middle fusiform gyrus (MFG, also called the 'fusiform face area' or FFA), the inferior occipital gyrus (IOG, also called 'occipital face area' or OFA) and the posterior part of superior temporal sulcus (pSTS). These areas do not only respond when a face stimulus is detected in the visual field, they also process faces at a more fine-grained level. For instance, pSTS is highly sensitive to facial expression and gaze, while MFG and IOG are sensitive to the perception of individual faces (Gauthier et al., 2000; Grill-Spector, Knouf, \& Kanwisher, 2004; Rotshtein, Henson, Treves, Driver, \& Dolan, 2005; Schiltz \& Rossion, 2006; Sergent, Ohta, \& MacDonald, 1992). The strongest evidence for face 


\section{Copyright (C) The British Psychological Society \\ Reproduction in any form (including the internet) is prohibited without prior permission from the Society}

individuation in these areas comes from so-called fMR-adaptation studies. When a stimulus is repeated, neural response in the activated neural population generally decreases (see Henson, 2003 for a review). The sensitivity of the neural population showing this adaptation can be inferred by measuring the extent to which its response to a given manipulated parameter recovers from adaptation. To illustrate, larger facepreferring activations are reported when participants are stimulated with blocks of different face identities than when of a single face is repeated all over the block (Gauthier et al., 2000; Grill-Spector \& Malach, 2001). This finding is taken to indicate that the sensitivity of face-preferring regions to inter-individual face differences. In two recent fMRI studies, it was demonstrated that recovery from adaptation in bilateral MFG is strong for upright faces, but eliminated or strongly reduced for inverted faces (Mazard, Schiltz, \& Rossion, 2006; Yovel \& Kanwisher, 2005). Moreover, Yovel and Kanwisher (2005) demonstrated that the inversion-related decrease of MFG response strongly correlated with its behavioural counterpart, thus localizing the neural source of behavioural IE in the face-preferring network located in bilateral MFG.

The fact that MFG face-preferring voxels are more sensitive to inter-individual differences when faces are presented in upright than inverted orientation indirectly suggests that they discriminate faces based on orientation-sensitive cues such as spatial configuration of the face. However, the kind of spatial relations that are processed as a basis for face individuation in the human brain, in particular in MFG, is still unspecified.

Indeed, each individual face is defined by multiple spatial relations (Farkas, 1994; Shi, Samal, \& Marx, 2006). While horizontal spatial relations such as inter-ocular distance characterize face symmetry, vertical relations such as eyes, nose, or mouth height within the face stimulus generally characterize its aspect ratio (see Lee \& Freire, 1999; Figure 1). Until recently, it was implicitly assumed that all kinds of spatial relations equally contribute to face perception and are equally affected by inversion. Horizontal and vertical relational changes were thus generally confounded in past studies on face configural perception (e.g. Freire, Lee, \& Symons, 2000b; Goffaux, Hault, Michel, Vuong, \& Rossion, 2005; Mondloch, Le Grand, \& Maurer, 2002; Murray, Yong, \& Rhodes, 2000; Yovel \& Kanwisher, 2004). However, in three behavioural experiments (Goffaux \& Rossion, 2007), we recently demonstrated that inversion of the face affects mostly the perception of vertical relations (e.g. eye or mouth height) while it affects the processing of local features and of horizontal relations (e.g. inter-ocular distance) equally and to a far lesser extent (see also Goffaux, in press). The weaker IE observed for horizontal relations and features suggests that these are processed at a rather local scale. In contrast, the large IE observed for vertical relations suggests their predominant role in upright face configural processing.

The aim of the present fMRI studies was to examine the impact of inversion on individual face discrimination in MFG and IOG face-preferring regions, by separating the contribution of featural information and these different types of spatial relations between features. In two fMRI experiments, participants viewed upright and inverted pairs of identical or different faces. Faces differed either at the level of vertical relations (eyes height), horizontal relations (inter-ocular distance), or local feature properties (eyes shape and surface; see Figure 1). In line with previous findings, we expected fMRI activation to face differences in the fusiform gyrus to decrease with inversion (Mazard et al., 2006; Yovel \& Kanwisher, 2005). Moreover, by investigating horizontal and vertical relations separately, we sought to specify the contribution of the face-preferring regions to the various aspects of face information. 


\section{Copyright (C) The British Psychological Society}

Reproduction in any form (including the internet) is prohibited without prior permission from the Society

Valerie Goffaux et al.
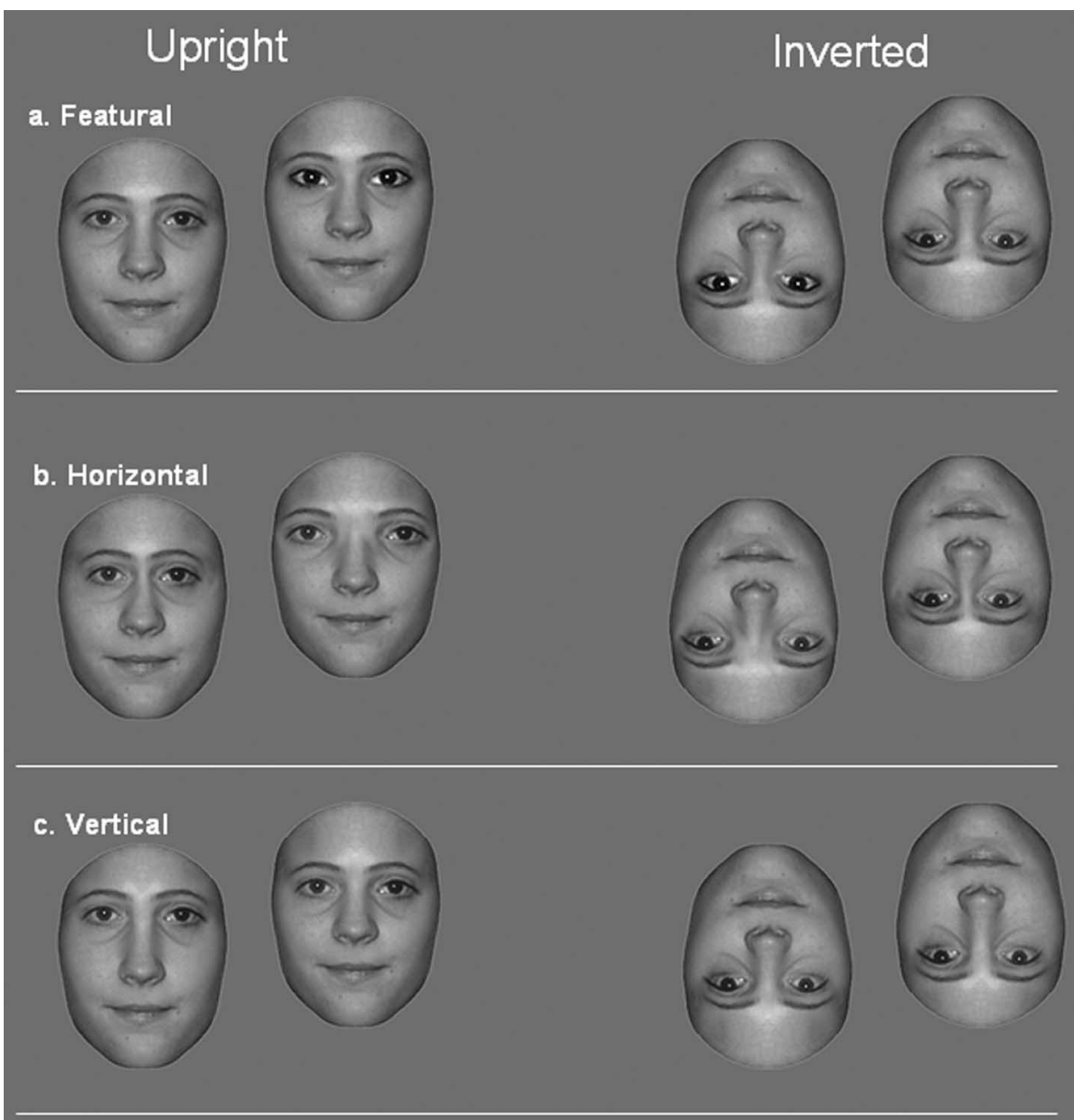

\section{d. Different}

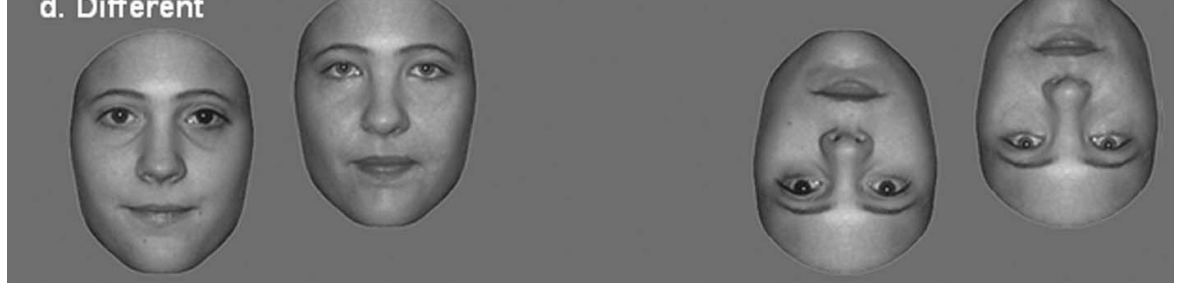

Figure I. Example of the various types of face differences presented upright (left column) and inverted (right column). The top row (a) shows a featural face pair, in which eye shape differed between target and probe faces. (b) Horizontal face pair, in which inter-ocular distance varied between target and probe faces by moving each eye by 15 pixels. (c) Vertical face pair, in which eye height was manipulated by moving each eye by 15 pixels. (d) Faces in a different pair differed at the level of all inner features (eyes, nose, and mouth).

In a first experiment, face pairs from the various conditions were presented in separate blocks and participants performed an orthogonal colour detection task. However, because condition blocking may elicit unnatural strategies to process featural and relational face differences, we also tested our hypotheses in an ER paradigm, in 


\section{Copyright (C) The British Psychological Society \\ Reproduction in any form (including the internet) is prohibited without prior permission from the Society}

which participants actively discriminated face pairs. ER experiment thus matched more closely the experimental conditions used in our previous behavioural investigations. Moreover, by measuring matching performance in the scanner, we explored the relationship between IE observed on behavioural and hemodynamic responses in the various face-preferring cortical regions. Since the contribution of relational versus featural cues in face perception may largely differ across individuals (see Rotshtein, Geng, Driver, \& Dolan, 2007), averaging neural activity in the various stimulus conditions may mask the functional contribution of these cues. With correlation analyses, inter-individual differences in relational and featural processing were considered to localize neural foci predicting best the behavioural face IE.

\section{Materials and methods \\ Participants}

Twenty (12 in block experiment and 8 in ER experiment) adult participants with normal or corrected-to-normal vision (mean age $27 \pm 3.5,7$ males, 2 left-handed) gave informed written consent and were paid for their participation.

\section{Stimulation procedure}

Stimuli were greyscale pictures of faces (half male), houses, and objects. Scrambled faces were generated by Fourier phase randomization (using Matlab 7.0.1). Stimuli were projected by an LCD projector on a screen located at the end of the scanner bore (over the head of the participant). Participants viewed the stimuli via an angled mirror mounted on the head coil (viewing distance $=57 \mathrm{~cm}$ ). Stimulus presentation (using Eprime 1.1 PST, Inc. software) was triggered by the first MR pulse. Stimuli were presented on a grey background subtending $256 \times 256$ pixels $(5.7 \times 5.7$ degrees of visual angle). All stimuli were matched for size, mean luminance, and root mean square (RMS) contrast. Faces of the same gender shared the same outer contour and eyebrows (as in Goffaux \& Rossion, 2007). Stimulus manipulations in block and ER experiments were thus only applied to inner face features (eyes, nose, and mouth).

In localizer runs, short blocks of faces, houses, objects and scrambled faces ( $N=20$ stimuli/block; block duration 24 seconds) were interleaved with fixation cross intervals (duration: 15 seconds). In a block of trials, stimuli appeared one by one during 700 milliseconds followed by a 500 milliseconds blank. Stimulus location varied by 10 pixels in $x$ and $y$ planes with respect to the centre of the screen. In a run, there were three blocks of each condition (total $N=12$ blocks/run). All but one participant (for technical reasons) performed two localizer runs. All 20 exemplars of each stimulus category appeared in a block in randomized order. Participant's task was to press a key with the right index finger whenever they detected rare occurrences of red-colourized stimuli. There were up to four targets per block and the same number of targets for all conditions in total (12 targets/condition/run in total). This orthogonal colour detection task ensured participant's vigilance all along the experiment while keeping equal levels of arousal and performance across conditions.

In both block and ER experiments, only faces ( $N=16$ original faces, half male) were presented. Each original face was manipulated at the level of its inner features using Adobe Photoshop. We generated five manipulated versions that differed from the original either at the level of all inner features (i.e. eyes, nose, and mouth; different 


\section{Copyright (C) The British Psychological Society \\ Reproduction in any form (including the internet) is prohibited without prior permission from the Society}

\section{Valerie Goffaux et al.}

condition); only at the level of eyes ('feature' condition); at the level of horizontal relations (horizontal condition; e.g. eyes moved further apart or closer to the nose); or at the level of vertical relations (vertical condition, e.g. eyes moved upper or lower with respect to the nose; for a full description of stimulus generation, see Goffaux \& Rossion, 2007 ). Both the eyes and eyebrows were displaced in vertical and horizontal conditions in the face to avoid distorting local eye-eyebrow relationships, on which participants may rely to accomplish the task. Stimulus manipulations in featural, horizontal, and vertical (see Figure 1) were calibrated based on past behavioural studies in which we avoided face grotesqueness while matching discrimination performance across conditions at upright orientation.

In the block fMRI experiment, the different types of face manipulations were presented in separate blocks. Participants underwent four runs comprising each 20 stimulation blocks (block duration: 24.4 seconds) interleaved with 15 secondsfixation periods. In a block, 16 faces were presented in pairs $(N=8$ pairs/block $)$. BOLD response evoked in these blocks was compared to blocks that consisted in the repetition of a single face within and across pairs of a given block. There were eight blocks per condition ( $N=64$ trials/conditions) in the total experiment. Same, different, featural, horizontal, and vertical conditions were presented upright in half of the blocks $(N=10$ blocks) and inverted in the other half. Upright and inverted blocks were clustered to minimize eye-movements between blocks. Half of the participants started each of the four runs with 10 upright blocks whereas the other half started with 10 inverted blocks. In a pair, each face appeared for 550 milliseconds, separated by a 450 milliseconds blank screen. Face pairs were separated by 1,500-milliseconds fixation intervals. The first face appeared at the centre of the screen while the second face was randomly jittered by 10 pixels in both $x$ and $y$ planes. In a run, face pairs appeared twice: once upright and once inverted. In the block experiment, participant's task was similar to localizer task, namely to press a key for rare occurrences of red-colourized stimuli (four targets/condition/run). Red-colourized targets always appeared as the second stimulus of a pair so that participant had to attend to the whole pair and did not process faces independently from each other.

The ER experiment comprised six runs. Same, featural, horizontal, and vertical conditions were presented upright and inverted but an additional condition was included in which nose and mouth features varied. This condition was used as a catch condition to prevent exclusive attention to the eyes (Goffaux \& Rossion, 2007); it was not analysed further to preserve statistical power to same, vertical, featural, and horizontal conditions, for which we had specific a priori hypotheses. Orientation and stimulus conditions were randomly interleaved in a run. Participants were instructed to report whether faces in a pair were the same or different (right index and right middle finger press, respectively). In order to maintain attention and motivation during this challenging task, participants were informed about their responses accuracy at the end of each run. In a pair, each face appeared for 400 milliseconds, separated by a 450 milliseconds blank screen. The second face of a pair was randomly jittered as in block experiment. An average 10-second interval (range: 8,750-11,250 milliseconds) separated trials to let BOLD response return back to baseline level. Prior to being scanned, participants were shortly familiarized with the task. They were naive as to the manipulations applied to the faces and were just informed that differences to report were really subtle. Each run comprised eight face pairs per condition ( $N=80$ trials per run) making a total of 48 trials per condition over the experiment. 


\title{
Copyright (C) The British Psychological Society \\ Reproduction in any form (including the internet) is prohibited without prior permission from the Society
}

Face vertical relations in occipito-temporal cortex

\begin{abstract}
Scanning procedure
Imaging was performed on a 3T head scanner at the University of Maastricht (Allegra, Siemens Medical Systems, Erlangen, Germany) provided with standard head coil. T2*weighted echo-planar imaging (EPI) was performed using BOLD contrast effect as an indirect marker of local neuronal activity (Ogawa, Lee, Kay, \& Tank, 1990). The acquisition parameters were identical across localizer and block fMRI experiments, twenty-five $3.5 \mathrm{~mm}$ oblique coronal slices (no gap, $\mathrm{TR}=1,500$ milliseconds, $\mathrm{TE}=28$ milliseconds, flip angle $(\mathrm{FA})=67^{\circ}, \quad$ matrix size $=64 \times 64, \quad \mathrm{FOV}=224 \mathrm{~mm}, \quad$ in-plane resolution $3.5 \times 3.5 \mathrm{~mm}$ ). Localizer runs lasted for 324 TRs each ( 8 minutes 6 seconds). In the block experiment, runs lasted for 537 TRs each (13 minutes 25 seconds). In the ER experiment, twenty-one $3.5 \mathrm{~mm}$ oblique coronal slices (no gap, TR $=1,250$ milliseconds, $\mathrm{TE}=28$ milliseconds, $\mathrm{FA}=67^{\circ}$ ) were acquired. In this slow ER experiment, the runs lasted for 738 TRs (13 minutes 22 seconds). A high-resolution T1-weighted anatomical data set encompassing the whole head was acquired by means of a 'modified driven equilibrium fourier transform' sequence (MDEFT, TR $=7.92$ milliseconds, $\mathrm{TE}=2.4$ milliseconds, $\mathrm{FA}=15^{\circ}$, matrix size $=256 \times 256, \mathrm{FOV}=256 \mathrm{~mm}^{2}, 176$ slices, slice thickness $=1 \mathrm{~mm}$, no gap, total run time $=13$ minutes and 43 seconds).
\end{abstract}

\section{Data analysis}

Functional and anatomical images were analysed using BrainVoyager QX (version 1.7, Brain Innovation, Maastricht, The Netherlands). The first volumes were skipped to avoid T1 saturation effect ( $N=2$ volumes in localizer and block experiments; $N=4$ volumes in ER experiment). Functional runs then underwent several pre-processing steps: correction of inter-slice scan time differences; linear trend removal; temporal high-pass filtering (to remove frequencies lower than four cycles per time course in localizer experiment, five cycles per time course in block experiment and three cycles per time course in ER experiment); and correction for inter-scan 3D rigid head motion (translation and rotation of all functional volumes to align them to the same reference volume). Gaussian temporal smoothing ( 2.8 seconds FWHM) was only applied to block and localizer experiments. Anatomical and functional data were spatially normalized to Talairach coordinate system (Talairach \& Tournoux, 1988) with a resolution of $3 \times 3 \times 3 \mathrm{~mm}$ using trilinear interpolation.

\section{Localizer statistical analyses}

The fMRI signal in the localizer runs was analysed using single-participant general linear model (GLM) computed over multiple runs. The predictor time courses for stimulation blocks were constructed as box-car functions filtered through a linear model indirectly relating neural activity and BOLD response (Boynton, Engel, Glover, \& Heeger, 1996). For anatomical reference, the statistical maps were overlaid on Talairach-normalized individual anatomical volumes.

The areas responding preferentially to faces were defined independently for each participant by the conjunction between [faces-objects] and [faces-scrambled] contrasts (Figure 2; Tables 1 and 2). Objects and faces stimuli were matched for mean luminance and RMS contrast while faces and their scrambled counterpart were matched for mean luminance, RMS contrast as well as spectral composition. This conjunction of contrasts thus ensured that larger activations for faces were related to high-level face perception independently from lower-level differences (i.e. mean contrast or spectral composition) known to differ across visual categories such as faces, houses and objects in general (Bosworth, Bartlett, \& Dobkins, 2006). 


\section{Copyright () The British Psychological Society}

Reproduction in any form (including the internet) is prohibited without prior permission from the Society

52 Valerie Goffaux et al.

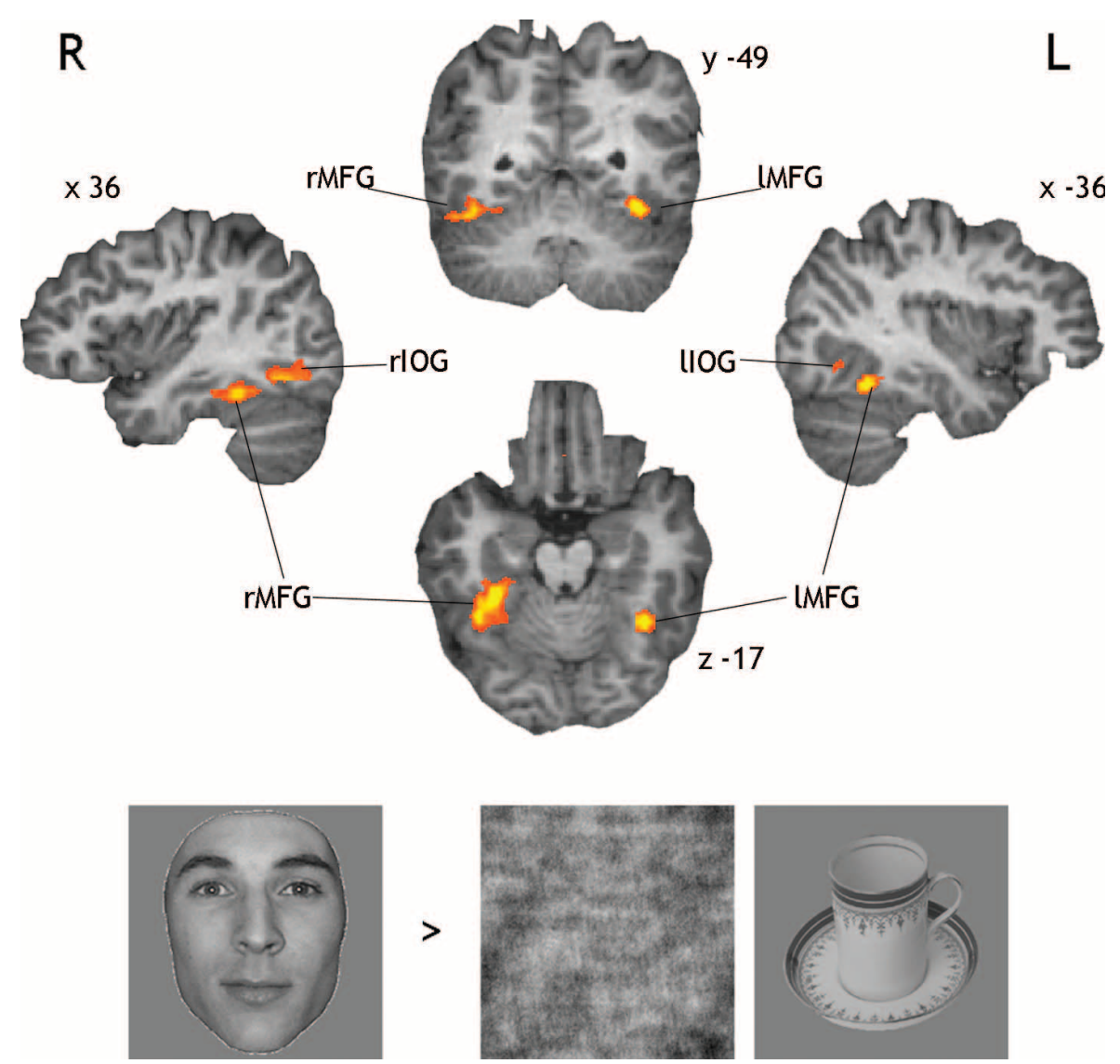

Figure 2. Face-preferring regions are shown for one representative participant of the block experiment $(q(\mathrm{FDR})<.02$; MFG $=$ middle fusiform gyrus; IOG $=$ inferior occipital gyrus). Bilateral MFG and IOG showed a significantly larger neural response for faces than for objects and scrambled stimuli.

Table I. Talairach coordinates (mean and standard errors) of ROls in block experiment

\begin{tabular}{lrrrrr}
\hline & \multicolumn{3}{c}{ Talairach coordinates } & \\
\cline { 3 - 5 } ROI & $N$ & \multicolumn{1}{c}{$x$} & $y$ & $z$ & Voxel size \\
\hline rMFG & $12 / 12$ & $40 \pm 5$ & $-47 \pm 8$ & $-14 \pm 5$ & 212 \\
IMFG & $11 / 12$ & $-37 \pm 4$ & $-47 \pm 7$ & $-13 \pm 6$ & 167 \\
rIOG & $9 / 12$ & $37 \pm 7$ & $-73 \pm 11$ & $-8 \pm 5$ & 124 \\
IIOG & $8 / 12$ & $-36 \pm 9$ & $-68 \pm 8$ & $-6 \pm 6$ & 49 \\
rPHG & $12 / 12$ & $27 \pm 1$ & $-36 \pm 2$ & $-9 \pm 2$ & 851 \\
IPHG & $12 / 12$ & $-25 \pm 4$ & $-42 \pm 9$ & $-9 \pm 6$ & 468 \\
rVLOC & $12 / 12$ & $35 \pm 9$ & $-74 \pm 9$ & $-6 \pm 5$ & 781 \\
IVLOC & $12 / 12$ & $-33 \pm 7$ & $-75 \pm 5$ & $-9 \pm 4$ & 446 \\
\hline
\end{tabular}




\section{Copyright (C) The British Psychological Society}

Reproduction in any form (including the internet) is prohibited without prior permission from the Society

Table 2. Talairach coordinates (mean and standard errors) of ROls in ER experiment

\begin{tabular}{|c|c|c|c|c|c|}
\hline \multirow[b]{2}{*}{ ROI } & \multirow[b]{2}{*}{$N$} & \multicolumn{3}{|c|}{ Talairach coordinates } & \multirow[b]{2}{*}{ Voxel size } \\
\hline & & $x$ & $y$ & $z$ & \\
\hline rMFG & $7 / 8$ & $36 \pm 1$ & $-46 \pm 3$ & $-14 \pm 2$ & 754 \\
\hline IMFG & $8 / 8$ & $-39 \pm 1$ & $-50 \pm 3$ & $-14 \pm 2$ & 594 \\
\hline rIOG & $5 / 8$ & $39 \pm 1$ & $-70 \pm 4$ & $-8 \pm 1$ & 218 \\
\hline IIOG & $6 / 8$ & $-40 \pm 2$ & $-7 \mid \pm 3$ & $-5 \pm 2$ & 49 \\
\hline rPHG & $8 / 8$ & $25 \pm 3$ & $-44 \pm 3$ & $-7 \pm 1$ & 392 \\
\hline IPHG & $8 / 8$ & $-26 \pm 1$ & $-44 \pm 3$ & $-7 \pm 1$ & 329 \\
\hline rVLOC & $8 / 8$ & $31 \pm 2$ & $-74 \pm 3$ & $-7 \pm 3$ & 757 \\
\hline IVLOC & $8 / 8$ & $-34 \pm 4$ & $-74 \pm I$ & $-6 \pm 2$ & 476 \\
\hline
\end{tabular}

All contiguous voxels in bilateral middle fusiform gyri (MFG) and inferior occipital gyri (IOG) significant on $t$ maps at an average $q$ (false discovery rate, (FDR)) $<.01$ were selected as regions of interest (ROIs) for further analysis (see Figure 2). In two participants, larger activations to faces than objects were extensive and overlapped MFG and IOG; in these participants, we ran a more severe contrast and selected face-preferring regions that were consistent across runs (i.e. the conjunction between (faces 1-objects 1), (faces 1-scrambled 1), (faces 2-objects 2), and (faces 2 -scrambled 2) contrasts). In three participants, we had to lower the statistical threshold $(q(\mathrm{FDR})<.09$ on average $)$ due to the smaller size of their face-preferring regions.

To monitor the behaviour of other brain regions, we localized regions preferring objects over faces in each participant. The contiguous voxels in the parahippocampal gyrus (PHG) that were more activated for objects and houses than for faces (e.g. Epstein \& Kanwisher, 1998) consistently across the two runs (conjunction between these contrasts (objects 1-faces 1), (objects 2-faces 2), (houses 1-faces 1), and (houses 2faces 2 ) at $q(\mathrm{FDR})<.02$ on average) were selected as ROI for further analysis. In six participants, we had to collapse the two runs (conjunction between (objects 1 and 2faces 1 and 2) and (houses 1 and 2 -faces 1 and 2) contrasts at $q$ (FDR) $<.02$, on average) to obtain object-preferring foci.

Beside face- and object-preferring ROIs, we also explored ventral lateral occipital complex (vLOC). This region is involved in the recognition of all kinds of visual categories including faces as indicated by adaptation evidence (Grill-Spector et al., 1999; Sayres \& Grill-Spector, 2006). We localized VLOC in each participant by selecting the contiguous voxels on the ventral surface of occipital lobe that were more activated for objects than fixation across the two runs (conjunction between these contrasts: (objects 1-fixation 1) and (objects 2-fixation 2) at $p$ (Bonferroni corrected for multiple comparison) $<.002)$.

\section{Block and ER experiments statistical analyses}

We investigated the response of each individual ROIs during block and ER experiments (Table 2). We averaged the signal time course across events (blocks in block experiment and trials in ER experiment) in each condition and converted these time courses to percent signal change (PSC) relative to fixation baseline activity (baseline interval $=2 \mathrm{TR}$ of fixation prior to stimulation block onset in block 


\section{Copyright (C) The British Psychological Society \\ Reproduction in any form (including the internet) is prohibited without prior permission from the Society}

\section{Valerie Goffaux et al.}

experiment and four TR of fixation prior to trial onset in ER experiment; see Figures $3 \mathrm{a}$ and $4 \mathrm{a})$. Signal time course was then averaged for each participant in each condition (from +3 to +19 TR post-stimulation onset in block experiment; +2 to +7 TR post-stimulation onset in ER experiment). These intervals were selected to monitor BOLD response related to face stimuli while taking BOLD onset delay into account. We thus obtained averaged PSC and tested orientation and stimulus type effects in a repeated-measure ANOVA with two factors: orientation (upright vs. inverted) and stimulus (five conditions in the block design experiment; four conditions in the ER experiment). Whenever the ANOVA revealed a significant main effect or interaction, fisher LSD tests were used to compare conditions two by two. We also analysed accuracy and correct response times (RTs) of the colour detection tasks (localizer and block experiments) and of the matching task (ER experiment) performed in the scanner. To further explore the relationship between behavioural and hemodynamic IEs, we computed the magnitude of hemodynamic IE in each ROI of each participant (upright PSC minus inverted PSC; e.g. Yovel \& Kanwisher, 2005). This was done in every stimulus condition separately. Similarly, we computed the magnitude of behavioural IE in accuracy (upright accuracy minus inverted accuracy) and correct RT (inverted RT minus upright RT) in each participant and in each stimulus condition. These values were entered in a nonparametric correlation analysis (Spearman $\rho$ ).

\section{Results}

\section{Block inversion experiment}

Behavioural responses

Performance in the colour detection task was at ceiling since all the participants were $100 \%$ accurate in every condition. Mean response times did not differ across conditions (average $=505 \pm 48$ milliseconds).

\section{Face-preferring ROls}

Figure 3 illustrates the averaged time course (Figure $3 a$ ) and BOLD response (expressed in PSC, Figure 3b) of face-preferring MFG and IOG ROIS (localized separately for each participant; see methods and Figure 2).

In the right hemisphere, MFG response was stronger to upright than to inverted faces $(F(1,11)=5.79, p<.035$; see Figure 3$)$. Inversion significantly reduced rMFG activity in different, vertical, and horizontal conditions $(p s<.03)$ but not in same and featural conditions $(p s>.08)$. The only significant adaptation effect was obtained when comparing different to same condition at upright $(p<.04$; $p$ s $>.84$ in other stimulus conditions). Inversion eliminated this adaptation effect $(p>.3)$. In the 1MFG, the ANOVA did not reveal any significant effect or interaction $(p s>.18)$.

In the rIOG, none of the effects and interactions was significant ( $p$ s $>.37)$. In the IIOG, the interaction between the factors of orientation and stimulus was significant $(F(4,44)=2.72, p<.05)$. There was a significant adaptation effect when comparing same and different conditions at upright $(p<.01)$, but not at inverted orientation $(p=.8)$. Face inversion significantly decreased BOLD response to vertical condition $(p<.003)$ and marginally in the different condition $(p=.06)$. 


\section{Copyright (C) The British Psychological Society}

Reproduction in any form (including the internet) is prohibited without prior permission from the Society
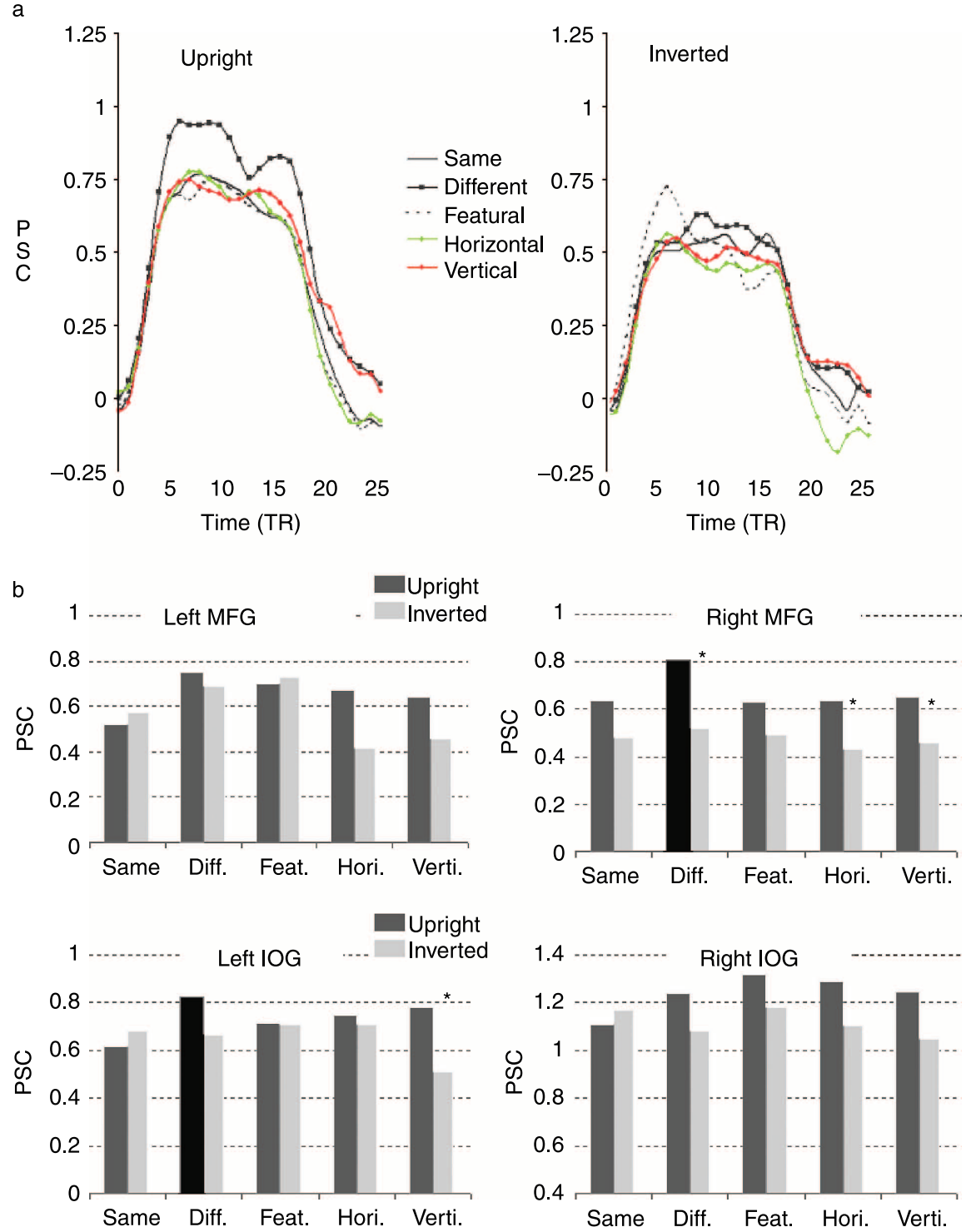

Figure 3. (a) Averaged and baseline-corrected time courses of right MFG activation in block experiment $(N=12)$. BOLD response to same, different, featural, vertical, and horizontal conditions are displayed for upright (left) and inverted (right) faces. (b) Averaged BOLD responses across orientation and stimulus conditions in face-preferring ROls of the block experiment (MFG = middle fusiform gyrus; IOG = inferior occipital gyrus). Asterisks indicate significant differences between upright and inverted conditions (i.e. IEs) and dark bars indicate conditions in which BOLD response significantly surpassed same level at upright (i.e. adaptation effect) but not at inverted orientation.

\section{Object-preferring and VLOC ROIs}

To exclude that these findings are due to non-specific hemodynamics, we tested the effects of orientation and stimulus conditions in regions responding more to objects than to faces, located bilaterally in PHG (Table 3). In the rPHG and in the PPHG, the 


\section{Copyright (C) The British Psychological Society}

Reproduction in any form (including the internet) is prohibited without prior permission from the Society

\section{Valerie Goffaux et al.}

activity level was close to zero (0.06 PSC in rPGH and - 0.02 PSC in IPGH on average; see Table 3). ANOVA computed on PPHG, IPHG, rVLOC, and IVLOC regions failed to reveal any significant effect or interaction (PHG: $p \mathrm{~s}>.2$; VLOC: $p \mathrm{~s}>.12$; Table 3 ).

Table 3. Mean BOLD responses across orientation and stimulus conditions in object-preferring ROls in block experiment $(N=12$; IVLOC = left ventral lateral occipital complex; rVLOC = right ventral lateral occipital complex; IPHG = left parahippocampal gyrus; rPHG = right parahippocampal gyrus)

\begin{tabular}{lcccc}
\hline & Same & Vertical & Horizontal & Featural \\
\hline $\begin{array}{l}\text { IVLOC } \\
\text { Upright } \\
\text { Inverted }\end{array}$ & 1.14 & & & \\
rVLOC & 1.37 & 1.3 & 1.36 & 1.37 \\
Upright & & 1.25 & 1.32 & 1.4 \\
Inverted & 1.11 & 1.43 & 1.4 & 1.34 \\
IPHG & 1.33 & 1.32 & 1.37 & 1.41 \\
Upright & & & & -0.02 \\
Inverted & -0.03 & 0.04 & -0.05 & -0.1 \\
rPHG & -0.06 & 0.04 & 0.03 & 0.08 \\
Upright & 0.05 & 0.1 & 0.02 & 0.05 \\
Inverted & 0.06 & 0.08 & 0.09 & \\
\hline
\end{tabular}

At upright, the adaptation effects were surprisingly scarce in the present experiment. They were only observed in the different condition in rMFG and IIOG, whereas neural activation to vertical, horizontal, and featural faces never significantly surpassed the level of BOLD response in same condition. The recovery from adaptation observed for different condition in rMFG and IIOG was eliminated by inversion. When stimulus conditions were separately considered, we found significant inversion-related decreases for different, horizontal, and vertical conditions in the rMFG. In IIOG, inversion selectively affected the vertical condition. None of these effects were significant in the non-face-preferring ROIs under study.

Featural, horizontal, and vertical variations were particularly subtle and the use of an orthogonal task likely allocated attentional resources away from these face variations. This may have strongly attenuated the recovery from adaptation in these stimulus conditions (see Yi, Kelley, Marois, \& Chun, 2006). For these reasons, we investigated ROI sensitivity to relational versus featural cues in upright and inverted faces in an ER design, which not only avoids the pitfalls related to blocked presentation but also enables the on-line monitoring of matching performance.

\section{ER inversion experiment}

\section{Behavioural responses}

As illustrated by Figure $4 \mathrm{~b}$, the behavioural performance of participants during scanning confirmed that inversion mostly damages the perception of vertical relations. ANOVA computed on accuracy and correct RT largely confirmed this pattern.

Orientation significantly influenced accuracy and RT (accuracy: $F(1,7)=25.93$, $p<.001$; RT: $F(1,7)=15.29, p<.006)$ with participants' responses being less accurate and delayed for inverted as compared to upright faces. The main effect of stimulus was significant on $\mathrm{RTs}(F(3,21)=5.30, p<.007)$ as horizontal condition was processed faster than vertical and same conditions $(p s<.03)$. These main effects were 


\section{Copyright (C) The British Psychological Society}

Reproduction in any form (including the internet) is prohibited without prior permission from the Society

moderated by orientation $\times$ stimulus interaction in both accuracy and RT (accuracy: $F(3,21)=5.65, p<.005$; RT: $F(3,21)=3.61, p<.03)$. We explored this interaction using post boc comparisons. The effect of inversion on accuracy was significant in vertical and same conditions (vertical: $p<.0001$; same: $p<.035$ ) but not in featural and horizontal conditions ( $p s>.6$ ). Inversion significantly slowed down RT in vertical, featural, and same conditions $(p s<.01)$, but not in horizontal condition $(p=.12)$. For both accuracy and RT, the magnitude of the IE was significantly larger in vertical than in featural and horizontal conditions (accuracy: $p$ s < .001; RT: $p$ s $<.03$ ) and marginally larger than in same conditions (accuracy: $p=.055 ; \mathrm{RT}: p=.06$ ).
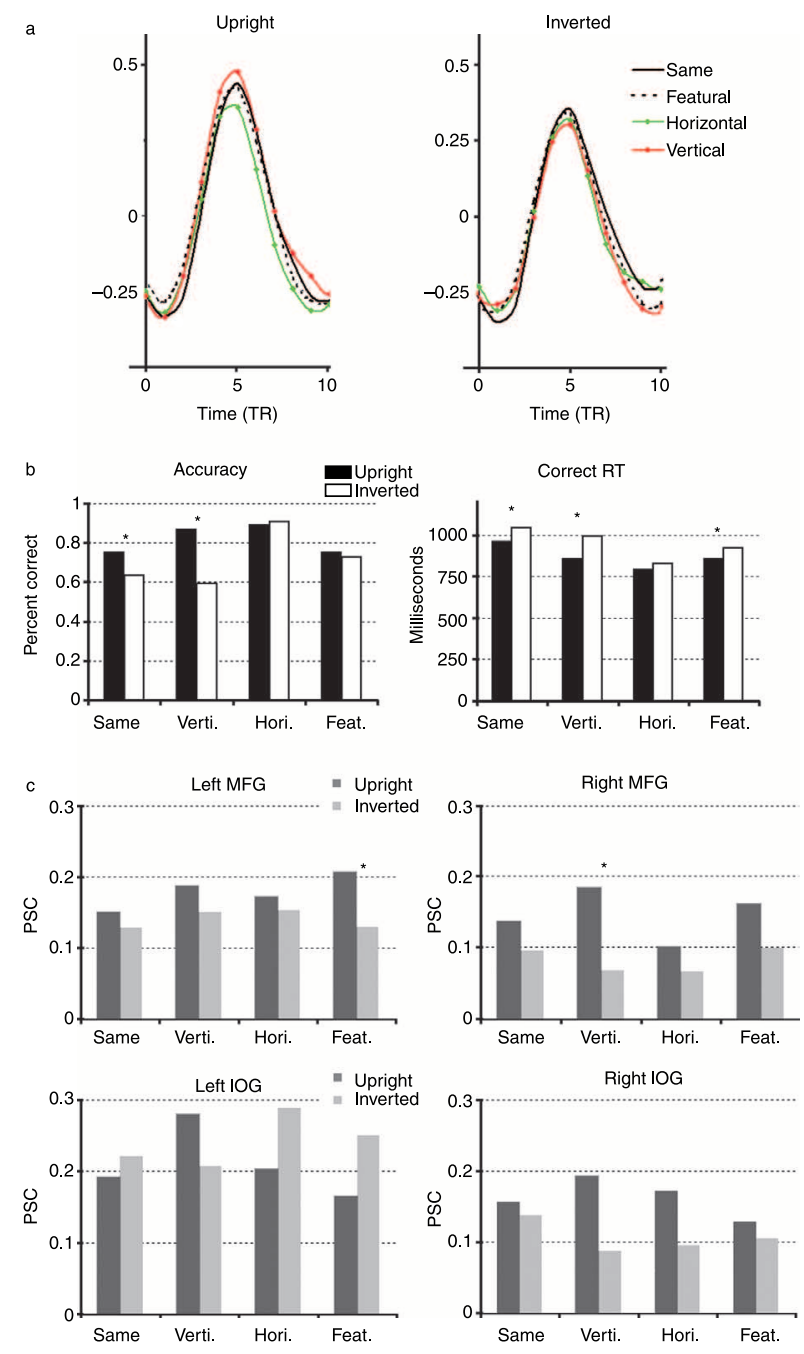

Figure 4. (a) Averaged and baseline-corrected time courses of right MFG activation in ER experiment $(N=8)$. BOLD response to same, featural, vertical, and horizontal conditions are displayed for upright (left) and inverted (right) faces. (b) Mean accuracy (percent correct) and correct response times (milliseconds) are plotted across all stimulus and orientation conditions asterisks indicate significant IEs. (c) BOLD responses across orientation and stimulus conditions in face-preferring ROIs (MFG = middle fusiform gyrus; IOG = inferior occipital gyrus). Asterisks indicate significant IEs. 


\section{Copyright (C) The British Psychological Society}

Reproduction in any form (including the internet) is prohibited without prior permission from the Society

\section{Valerie Goffaux et al.}

\section{Face-preferring ROIs}

Figure $4 \mathrm{a}$ depicts the averaged time course of rMFG activity in the various experimental conditions. In this region, the main effect of orientation was significant $(F(1,6)=8.367, p<.028$, see Figure $4 \mathrm{~b})$. Yet, inversion significantly decreased BOLD response in the vertical condition only $(p<.002$; other stimulus conditions: $p s>.08)$. None of the stimulus conditions led to higher BOLD response than same condition at upright ( $p s>.17)$. Still, it is interesting to note that BOLD response to vertical condition was significantly larger than to horizontal condition at upright $(p<.022)$, but not at inverted orientation $(p=1)$.

In IMFG, the main effect of orientation just missed significance $(F(1,7)=5.085$, $p<.06$ ). At upright, neural response was marginally higher in featural than in same condition $(p=.052)$. Inversion significantly decreased BOLD response in the featural condition only $(p<.01)$.

In rIOG and IIOG, ANOVA did not reveal any significant effect or interaction $(p s>.23)$.

\section{Object-preferring and VLOC ROIs}

Activity in PHG ROIs was close to zero (0.041 PSC in rPGH and 0.028 PSC in 1PGH on average; Table 4). Nevertheless, there was a significant main effect of stimulus in IPHG $(F(3,21)=4.21, p<.02)$. IPHG response was significantly larger in vertical $(p<.002)$ and horizontal conditions $(p<.02)$ than in same condition (when upright and inverted trials are collapsed). In the rPHG, none of these effects was significant $(p s>.122)$.

Table 4. Mean BOLD responses across orientation and stimulus conditions in object-preferring ROls in ER experiment $(N=8$; IVLOC $=$ left ventral lateral occipital complex; $r V L O C=$ right ventral lateral occipital complex; IPHG = left parahippocampal gyrus; rPHG = right parahippocampal gyrus)

\begin{tabular}{lcccc}
\hline & Same & Vertical & Horizontal & Featural \\
\hline $\begin{array}{l}\text { IVLOC } \\
\text { Upright }\end{array}$ & 0.21 & 0.26 & & \\
Inverted & 0.31 & 0.31 & 0.24 & 0.23 \\
rVLOC & & & 0.31 & 0.3 \\
Upright & 0.2 & 0.2 & 0.18 & 0.18 \\
Inverted & 0.22 & 0.25 & 0.25 & 0.23 \\
IPHG & -0.05 & 0.07 & 0.03 & 0.02 \\
Upright & 0 & 0.05 & 0.06 & 0.06 \\
Inverted & -0.01 & 0.07 & 0.02 & 0.01 \\
rPHG & 0.04 & 0.07 & 0.09 & 0.07 \\
Upright & & & & \\
Inverted & & & & \\
\hline
\end{tabular}

In the rVLOC, the ANOVA failed to reveal any significant effect $(p s>.16)$. In contrast, there was a significant main effect of orientation in $\operatorname{IVLOC}(F(1,7)=7.12$, $p<.032)$ as inversion overall increased BOLD response. Yet, when stimulus conditions are examined separately, this increase was only significant for same and horizontal conditions $(p s<.04)$. 


\title{
Copyright (C) The British Psychological Society
}

\author{
Reproduction in any form (including the internet) is prohibited without prior permission from the Society
}

\section{Correlation between behavioural and hemodynamic inversion effects}

The results described above indicate that face orientation modulates the average response of several cortical regions. Another way to address the sensitivity of cortical processing to face inversion is to test the correlation between behavioural (accuracy and correct RT) and hemodynamic IE. The advantage of correlation analyses is that they take the whole range of inter-individual differences in neural responses into account and test whether these can reliably predict by inter-individual behavioural differences (see Jacques \& Rossion, 2007). Neural IE significantly correlated with their respective behavioural counterpart (in accuracy or RT) in two stimulus conditions: vertical and horizontal conditions. Interestingly, these correlations in horizontal and vertical conditions arose in distinct cortical regions.

On average, rMFG decreased its neural response when processing inverted faces and especially when these differed at the level of vertical relations. Correlation analyses revealed that the magnitude of this neural IE was tightly related to the inversion-related drop of accuracy for vertical relations $(\rho=.89, p<.01$; Figure 5$)$. In contrast, there was no such relation in horizontal condition (accuracy-BOLD IE: $\rho=-.54, p=.21$; RTBOLD IE: $.6, p=.16$ ).

Although inversion decreased 1MFG average activity when participants had to process featural variations, there was no correlation between behavioural and hemodynamic IE in the featural condition (accuracy-BOLD IE: $\rho=.4, p=.4$; RT-BOLD IE: $\rho=.61, p=.14)$. Yet, despite IE in horizontal condition being weak overall both in RT and MFG activity, there was a significant correlation between these two measures in

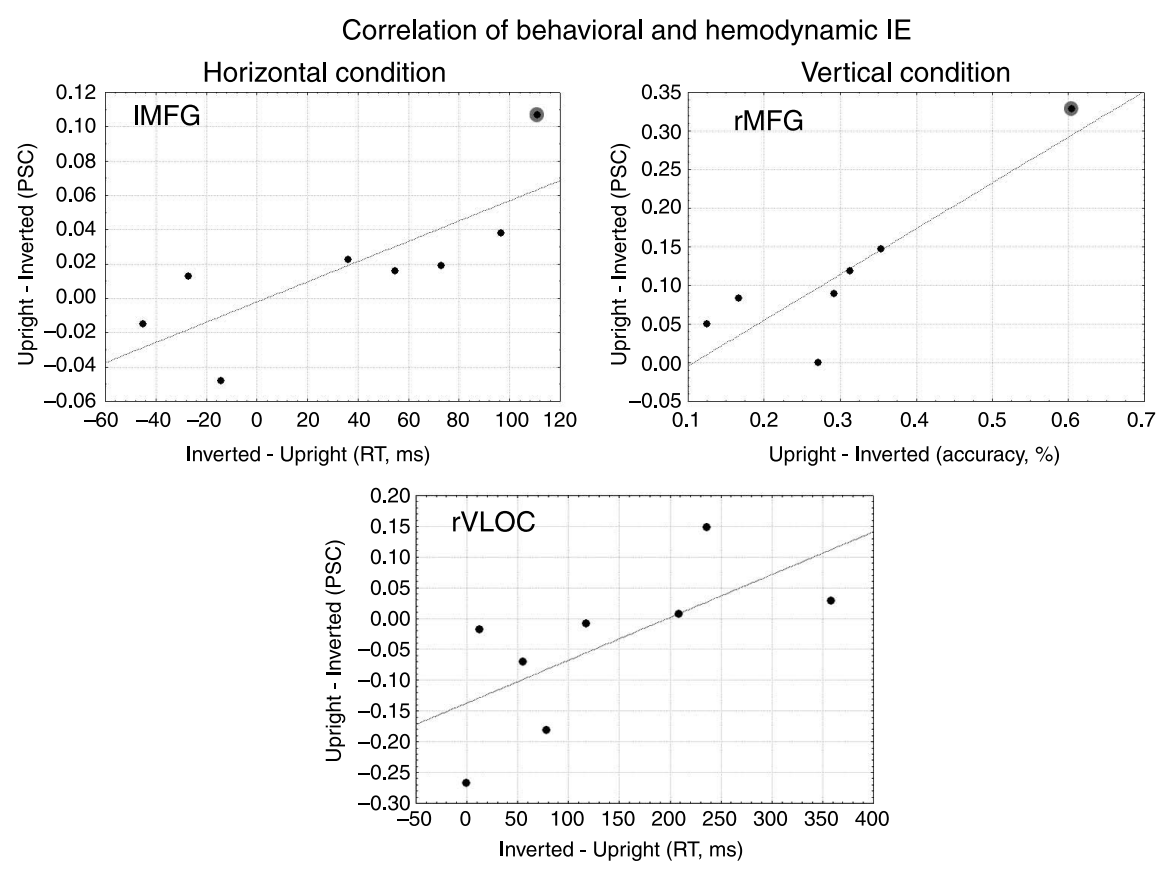

Figure 5. The magnitude of the IE in horizontal and vertical conditions significantly correlated with their respective behavioural counterpart in IMFG, rMFG, and rVLOC. The circles shaded in grey in IMFG and rMFG plots highlight outlier participants. 


\section{Copyright (C) The British Psychological Society \\ Reproduction in any form (including the internet) is prohibited without prior permission from the Society}

\section{Valerie Goffaux et al.}

IMFG $(\rho=.86, p<.01$; see Figure 5$)$. No such relation was observed in vertical condition (accuracy-BOLD IE: $\rho=-.03, p=.94$; RT-BOLD IE: $\rho=.53, p=.22$ ).

By looking at Figure 5, it appears that IMFG and rMFG correlations may be driven by outlier participants (shaded in grey on Figure 5). Correlations nonetheless remained strong and significant (rMFG: $\rho=.83, p<.01$; 1 MFG: $\rho=.78, p<.05$ ) even when excluding IMFG and rMFG respective outlier participants.

Surprisingly, there was also a strong correlation between RT and rVLOC activity at the level of vertical IE $(\rho=.88, p<.01)$. In the vertical condition, the slowing down of performance caused by inversion was indeed a good predictor of the inversion-related decrease of rVLOC activity. All other ROIs (rIOG, IIOG, IVLOC, rPHG, IPHG) failed to reveal any significant correlation with behaviour. The absence of correlation was not due to an overall lack of power in these regions since there were significant correlations across stimulus conditions when only neural activity was considered.

To summarize, the behavioural performance measured in the scanner indicated that face inversion affects vertical relations more severely than other face cues (confirming our recent behavioural results Goffaux \& Rossion, 2007). Neural activity in bilateral MFG was found to decrease with inversion. Yet, inversion-related decreases affected different stimulus conditions in IMFG and rMFG. In rMFG, the neural IE was significant in vertical condition only, whereas it was significant for featural condition only in IMFG. In contrast, IVLOC increased its response when faces were inverted but this effect was significant in horizontal and same conditions only. Using correlation analyses, we explored the relationship between behavioural and hemodynamic IE across stimulus conditions. Interestingly, significant behavioural-hemodynamic IE correlations were observed for vertical and horizontal conditions in rMFG and IMFG, respectively. The magnitude of vertical IE in rMFG reliably predicted the magnitude of its behavioural counterpart. In contrast, for IMFG, brain and hemodynamic IE magnitudes correlated in the horizontal condition. Although rVLOC average activity was not influenced by face orientation, inter-individual differences in neural vertical IE correlated with inter-individual differences in behavioural vertical IE in this region.

\section{General discussion}

In two fMRI experiments, we examined the impact of inversion on relational and featural processing in the face-preferring cortical network. Unlike previous studies, the contributions of horizontal and vertical spatial relations were considered separately since they have been shown to be differentially vulnerable to face inversion (Goffaux \& Rossion, 2007; see also Goffaux, in press). In both block and ER studies, we presented participants with pairs of faces that differed at the level either of a local feature, of vertical relations, or of horizontal relations of the same feature. In both experiments, neural response to faces largely decreased when these were inverted in the rMFG. In the ER experiment, both rMFG and IMFG activity decreased with inversion, but in distinct stimulus conditions. Whereas inversion affected IMFG processing only in featural condition, inversion selectively affected the processing of vertical relations in rMFG.

Our findings suggest that the spatial configuration of faces is mostly encoded in rMFG whereas the neuronal response in $1 M F G$ is largely invariant to face orientation and relies on more local aspects of face information. However, there were some discrepancies across block and ER findings. On the one hand, inversion affected rMFG activity in almost all stimulus conditions but did not affect IMFG activity in the 


\section{Copyright (C) The British Psychological Society \\ Reproduction in any form (including the internet) is prohibited without prior permission from the Society}

block experiment. On the other hand, inversion selectively affected the processing of vertical relations in rMFG and the processing of local features in IMFG in ER experiment. In other words, the profile of IE across stimulus conditions was more specific in the ER than in the block experiment. This could be due to the fact that neural activity measured in the block experiment was induced not only by the processing of featural, vertical, and horizontal within-pair variations but also by the perception of the more prominent across-pair identity changes. Neural IE measured in block experiment thus likely confounded neural IE at these two different levels, accounting for the lesser specificity of IE profile in block design. The less specific picture conveyed by block results is also obvious in upright conditions. In the block experiment, there was no difference between the neural responses induced by vertical and horizontal conditions, whereas the ER experiment revealed clearly stronger neural activity to vertical than to horizontal variations in upright faces. We will focus on ER results in the remaining of the discussion.

Our previous behavioural evidence demonstrated that the vulnerability of face processing to inversion relies on the disrupted extraction of vertical relations. The fact that the vertical IE is localized in rMFG suggests that this cortical region is the main site of upright configural face processing. This was largely confirmed by the correlation analyses, as inversion-related decrease of activity in rMFG reliably predicted the inversion-related accuracy drop in the vertical condition. Inversion most largely impairs the processing of vertical relational cues, but it also moderately affects the processing of local feature properties (Goffaux \& Rossion, 2007). In the ER experiment, the behavioural performance for processing featural variations was indeed slightly, but significantly, slower in inverted than upright faces. In parallel, IMFG activity significantly decreased when featural variations were presented upsidedown. Correlation analyses further indicated the involvement of $1 M F G$ in the processing of horizontal relations. Indeed, IMFG response to face horizontal relations across orientation reliably predicted the behavioural IE observed in this condition. It is thus interesting that the vulnerability of this local aspect of face information was again best reflected in IMFG activity.

In summary, we provide evidence that the processing of face configuration and its vulnerability to inversion mostly resides in the right-lateralized MFG. Since we failed to report any significant interaction between vertical versus horizontal relational processing and inversion, further investigation is needed to firmly establish the dissociate contribution of $1 M F G$ and rMFG to local and relational processes. Yet, other lines of evidence indicate that such dissociation is likely. Previous neuroimaging evidence indeed showed larger neural IE (e.g. Mazard et al., 2006; Yovel \& Kanwisher, 2004) and stronger configural/holistic processing (Rossion et al., 2000; Schiltz \& Rossion, 2006) in the right hemisphere. This is also in line with previous evidence from divided visual field behavioural studies (e.g. Hillger \& Koenig, 1991). Lesion studies also point to a greater contribution of the right hemisphere to the perception of faces and of their spatial relations. Brain lesions leading to prosopagnosia (an acquired deficit at individuating faces, Bodamer, 1947) are most often right-lateralized (e.g. Bouvier \& Engel, 2006; Sergent \& Signoret, 1992) and have been related to an impairment at holistic/configural face processing (e.g. Barton, Press, Keenan, \& O'Connor, 2002; Sergent \& Villemure, 1989). Moreover, early visual deprivation of the right hemisphere due to congenital cataracts have been shown to induce persistent deficits in the processing of face spatial relations in adulthood (Le Grand, Mondloch, Maurer, \& Brent, 2003; Le Grand et al., 2001). 


\section{Copyright (C) The British Psychological Society \\ Reproduction in any form (including the internet) is prohibited without prior permission from the Society}

\section{Valerie Goffaux et al.}

It is the first time, to our knowledge, that a neuroimaging study considers the various types of face spatial relations as differentially contributing to face perception. Three previous studies directly investigated the processing of spatial relations and features in the human brain, but they differed from the present work on several important aspects. Yovel and Kanwisher's (2004) investigated the contribution of bilateral MFG to the encoding of spatial relations versus features of faces (and houses). In their study, participants were presented with blocks of faces that were manipulated relationally (i.e. mouth was moved up and down, while the eyes were displaced horizontally), or featurally (i.e. both mouth and eyes replaced). They found larger MFG response to upright than to inverted faces; and this IE was the largest in the right hemisphere, as in the present study. However, the authors reported similar neural IE across featural and relational conditions and concluded that face relations and features undergo the same processing in face-preferring regions of the brain. This discrepancy between the findings of Yovel and Kanwisher (2004) and the present study can be accounted by several methodological aspects. First, these authors manipulated several features (eyes and mouth) at the same time in the featural condition; this likely engaged more global processes than expected by the authors. Indeed, the present study revealed large neural IE when several features were varied (cf. eyes, nose, and mouth in the different condition from block experiment). So, the number of altered features, and not only the way they are manipulated (i.e. local properties or spatial relations), may be a critical aspect to consider when attempting to selectively tap into featural versus relational processes. Second, Yovel and Kanwisher' (2004) study simultaneously manipulated the horizontal and vertical relations of faces, thus involving fundamentally different types of face processes (local vs. configural, respectively) in relational condition. Furthermore, Yovel and Kanwisher's participants were explicitly cued to attend relations or features that were varied in separate blocks. The combined use of blocked presentation and explicit cueing likely triggered artificial strategies to process featural and relational variations in that study. Overall, these methodological aspects may have largely attenuated the actual processing differences between featural and relational face processing as indicated by our unspecific block findings.

More recently, two neuroimaging papers supported past psychophysical evidence that featural and relational cues recruit seperate processing (Maurer et al., 2007; Rotshtein et al., 2007). Maurer and colleagues (2007) reported that face relations recruit a large network of regions, extending from fusiform to frontal cortex. This network was located in the right hemisphere and showed greater sensitivity to relational than to featural differences across faces, while regions encoding features were mostly found in the left hemisphere. In contrast to our findings, the left- and right-lateralized fusiform regions reported by Maurer and colleagues (2007) were adjacent to, but did not overlap with, face-preferring voxels. Rotshtein et al. (2007) investigated relational and featural processing using an immediate repetition paradigm in fMRI. They manipulated feature relations so slightly (relational variations subtended less than $1^{\circ}$ of visual angle) that they were hardly perceived by the participants and induced weak neural responses. Yet, using correlation analyses, the authors could demonstrate that the ability to process face relations was a good predictor of face recognition abilities at the behavioural level. Behavioural sensitivity to relations also correlated with neural activity in rMFG and bilateral IOG face-preferring regions. This agrees with our observation that RMFG and rIOG sensitivity to inversion reliably predicted IE on behavioural performance in vertical condition whereas local aspects of face information were represented in 1MFG. Nevertheless, Maurer et al.'s and Rotshtein et al's studies did not dissociate horizontal 


\section{Copyright (C) The British Psychological Society \\ Reproduction in any form (including the internet) is prohibited without prior permission from the Society}

and vertical relations and explored their processing at upright orientation only. It is thus difficult to quantify the engagement of orientation-sensitive configural processing in their respective experiments.

The present findings are also in line with an fMRI study (Schiltz \& Rossion, 2006), which explored the neural source of the well-known face composite illusion (Young, Hellawell, \& Hay, 1987). Composite faces are generated by combining upper and lower parts of different faces. When the upper part of a given face is spatially aligned with the lower part of another face, the visual system integrates them so strongly that a completely new face is perceived. Once composite faces are inverted, participants become better able to process parts independently from each other and composite illusion is strongly reduced. Although participants were instructed to allocate all their resources to the upper part of composite stimuli, Schiltz and Rossion (2006) reported that rMFG activity was larger when identical top face parts were combined with different bottom parts than when they were associated with identical bottom parts. This composite recovery from adaptation was eliminated by inversion, thus again indicating rMFG involvement in configural/holistic face processing. It is interesting to note that the composite illusion relies on the integration of face parts along the vertical axis. Here, without breaking face stimuli apart, we provide direct evidence that vertical relations are highly significant for integrating features into a configural/holistic representation and that such vertical integration largely occurs in rMFG.

Previous studies proposed that inversion decreases neural activity because faces look more similar when they are inverted, thus substantially attenuating the recovery from adaptation (i.e. neural activity difference between different vs. repeated conditions; Mazard et al., 2006; Yovel \& Kanwisher, 2005). In the block experiment, we observed significant recovery from adaptation at upright orientation only when all features differed in a face pair (the so-called different condition). Once inverted, neural activity to different condition decreased and recovery from adaptation was eliminated. However, in the other conditions, the significant inversion-related decreases in neural activity were not associated with significant recovery from adaptation at upright orientation. The fact that recovery from adaptation was observed in the block experiment only in the different condition suggests that face variations were too subtle in the featural, vertical, and horizontal conditions to induce significant recovery. Moreover, the orthogonal task performed in the block experiment (colour detection task) distracted participants' attentional resources away from the subtle face variations of interest. Recent evidence indicates that attention gates adaptation effects in highlevel visual cortex (Yi et al., 2006). In the ER experiment, participants performed an active matching task on featural, vertical, and horizontal pairs. Nevertheless, we still failed to observe any significant recovery from adaptation for upright featural, vertical, and horizontal face differences despite the fact that inversion significantly attenuated neural activity to most of these conditions. Rotshtein et al. (2007) also investigated neural adaptation to featural and relational variations of faces in an immediate repetition paradigm. While they reported significant recovery from adaptation when the local properties of all features (like in our different condition, block experiment) were varied in upright face pairs, no such recovery was observed when feature relations only were manipulated. Rotshtein et al. (2007) suggested that the lack of recovery in relational condition is due to the difficulty in perceiving relational changes. Here, we show that even when difficulty is matched across upright conditions, relational and featural face variations fail to induce significant recovery from adaptation. It is thus more likely that the subtlety of local featural, vertical, 


\section{Copyright (C) The British Psychological Society \\ Reproduction in any form (including the internet) is prohibited without prior permission from the Society}

\section{Valerie Goffaux et al.}

and horizontal variations fully accounts for the absence of adaptation recovery in our experiments.

In both experiments, we explored the neural response of object-preferring regions located in PHG and of ventral LOC in order to evaluate the face-specificity of our results. The largest BOLD IE observed for vertical relations did not replicate in these regions, indicating that this effect is specific to high-level processing of faces. Nevertheless, IVLOC region was found to increase its activity when faces were inverted. This has already been reported by others (Epstein, Higgins, Parker, Aguirre, \& Cooperman, 2006; Yovel \& Kanwisher, 2005). The lack of correlation with behavioural IE (also in Yovel \& Kanwisher, 2005) indicates that inversion-related increase in IVLOC activity is not the neural source of face IE. In contrast, correlation analyses revealed a relation between neuronal activity changes in the rVLOC and the behavioural IE observed for vertical relations, despite the fact that inversion did not modulate the average activity of this region. Object-preferring voxels located in IPHG activity increased in response to vertical and horizontal variations. Unlike face-preferring regions located in bilateral MFG, stimulus influences on PHG activity were orientation-independent. The sensitivity of PHG and VLOC to the present experimental manipulations suggests that the encoding of individual face information engages a large network of visual areas, and not only those regions that show preference for faces (Dricot, Sorger, Schiltz, Goebel, \& Rossion, 2008; Haxby et al., 2001).

The regions targeted by the present study show a preference for face stimuli but nevertheless respond to other object classes to a lesser extent, probably because they encompass clusters of neurons that are not face-preferring (e.g. Grill-Spector, Sayres, \& Ress, 2006). Here we show that these regions are particularly sensitive to relations between features of the upright faces, in particular vertical relations. It remains to be clarified whether these observations may extend to other object classes or not. Interestingly, IE as large as those obtained for faces have been reported for body images (Reed, Stone, Bozova, \& Tanaka, 2003). As we pointed out previously (Goffaux \& Rossion, 2007), bodies resemble faces on several aspects: social significance, mono-orientation, surface composition, but also vertical axis of elongation. Since recent neuroimaging studies have demonstrated very close activations in the fusiform gyrus to pictures of faces and bodies (Schwarzlose, Baker, \& Kanwisher, 2005), it would be interesting to test whether IEs due to disruption of vertical relations extend to this non-face category.

In conclusion, the present study indicates that (1) vertical, horizontal, and featural cues carry different information for the perception of upright faces and involve different neural processes and (2) the vulnerability of face perception to inversion stems mainly from the disrupted processing of vertical face relations in the network of face-preferring cortical regions of the right hemisphere (rMFG, rIOG). These findings thus corroborate the view that vertical relations drive the configural/holistic integration of features that is particular to upright face processing. Moreover, they indicate the right but not left MFG as the main site for face configural processing and upright face individuation skills more generally.

\section{Acknowledgements}

Valerie Goffaux and Bruno Rossion are supported by the Belgian National Foundation for Scientific Research (FNRS). The authors are grateful to Russel Epstein for providing house pictures and to 


\title{
Copyright (C) The British Psychological Society
}

\author{
Reproduction in any form (including the internet) is prohibited without prior permission from the Society
}

Armin Heinecke for assistance in statistical analyses. This study was funded by a research grant of the FNRS to Bruno Rossion and by the University of Maastricht.

\section{References}

Bartlett, J. C., \& Searcy, J. (1993). Inversion and configuration of faces. Cognitive Psychology, 25(3), 281-316.

Barton, J. J., Press, D. Z., Keenan, J. P., \& O'Connor, M. (2002). Lesions of the fusiform face area impair perception of facial configuration in prosopagnosia. Neurology, 58(1), 71-78.

Bodamer, J. (1947). Die-prosop-agnosie. Archives of Psychiatrie Nervenkrankhe, 179, 6-54.

Bosworth, R. G., Bartlett, M. S., \& Dobkins, K. R. (2006). Image statistics of American Sign language: Comparison with faces and natural scenes. Journal of the Optical Society of America A, 23, 2085-2096.

Bouvier, S. E., \& Engel, S. A. (2006). Behavioral deficits and cortical damage loci in cerebral achromatopsia. Cerebral Cortex, 16(2), 183-191.

Boynton, G. M., Engel, S. A., Glover, G. H., \& Heeger, D. J. (1996). Linear systems analysis of functional magnetic resonance imaging in human V1. Journal of Neuroscience, 16(13), 4207-4221.

Dricot, L., Sorger, B., Schiltz, C., Goebel, R., \& Rossion, B. (2008). The roles of 'face' and 'non-face' areas during individual face perception: Evidence by fMRI adaptation in a brain-damaged prosopagnosic patient. Neuroimage, 40(1), 318-332.

Epstein, R., \& Kanwisher, N. (1998). A cortical representation of the local visual environment. Nature, 392(6676), 598-601.

Epstein, R. A., Higgins, J. S., Parker, W., Aguirre, G. K., \& Cooperman, S. (2006). Cortical correlates of face and scene inversion: A comparison. Neuropsychologia, 44(7), 1145-1158.

Farkas, L. G. (1994). Anthropometry of the head and face. New York: Raven Press.

Freire, A., Lee, K., \& Symons, L. A. (2000a). The face-inversion effect as a deficit in the encoding of configural information: Direct evidence. Perception, 29(2), 159-170.

Freire, A., Lee, K., \& Symons, L. A. (2000b). The face-inversion effect as a deficit in the encoding of configural information: Direct evidence. Perception, 29(2), 159-170.

Gauthier, I., Tarr, M. J., Moylan, J., Skudlarski, P., Gore, J. C., \& Anderson, A. W. (2000). The fusiform 'face area' is part of a network that processes faces at the individual level. Journal of Cognitive Neuroscience, 12(3), 495-504.

Goffaux, V. (in press). The horizontal and vertical relations in upright faces are transmitted by different spatial frequency ranges. Acta Psychologica.

Goffaux, V., Hault, B., Michel, C., Vuong, Q. C., \& Rossion, B. (2005). The respective role of low and high spatial frequencies in supporting configural and featural processing of faces. Perception, 34(1), 77-86.

Goffaux, V., \& Rossion, B. (2007). Face inversion disproportionately impairs the perception of vertical but not horizontal relations between features. Journal of Experimental Psychology: Human Perception and Performance, 33(4), 995-1002.

Grill-Spector, K., Kushnir, T., Edelman, S., Avidan, G., Itzchak, Y., \& Malach, R. (1999). Differential processing of objects under various viewing conditions in the human lateral occipital complex. Neuron, 24, 187-203.

Grill-Spector, K., Knouf, N., \& Kanwisher, N. (2004). The fusiform face area subserves face perception, not generic within-category identification. Nature Neuroscience, 7(5), 555-562.

Grill-Spector, K., \& Malach, R. (2001). fMR-adaptation: A tool for studying the functional properties of human cortical neurons. Acta Psychologica, 107(1-3), 293-321.

Grill-Spector, K., Sayres, R., \& Ress, D. (2006). High-resolution imaging reveals highly selective nonface clusters in the fusiform face area. Nature Neuroscience, $9(9), 1177-1185$. 


\section{Copyright (C) The British Psychological Society}

Reproduction in any form (including the internet) is prohibited without prior permission from the Society

\section{Valerie Goffaux et al.}

Haxby, J. V., Gobbini, M. I., Furey, M. L., Ishai, A., Schouten, J. L., \& Pietrini, P. (2001). Distributed and overlapping representations of faces and objects in ventral temporal cortex. Science, 293(5539), 2425-2430.

Henson, R. N. (2003). Neuroimaging studies of priming. Progress in Neurobiology, 70(1), 53-81.

Hillger, L. A., \& Koenig, O. (1991). Separable mechanisms in face processing: Evidence from hemispheric specialization. Journal of Cognitive Neuroscience, 3, 42-58.

Jacques, C., d'Arripe, O., \& Rossion, B. (2007). The time course of the inversion effect during individual face discrimination. Journal of Vision, 7(8), 3.

Jacques, C., \& Rossion, B. (2007). Early electrophysiological responses to multiple face orientations correlate with individual discrimination performance in humans. Neuroimage, 36(3), 863-876.

Le Grand, R., Mondloch, C. J., Maurer, D., \& Brent, H. P. (2001). Neuroperception: Early visual experience and face processing. Nature, $410,890$.

Le Grand, R., Mondloch, C. J., Maurer, D., \& Brent, H. P. (2003). Expert face processing requires visual input to the right hemisphere during infancy. Nature Neuroscience, 6(10), 1108-1112.

Lee, K., \& Freire, A. (1999). Effects of face configuration change on shape perception: A new illusion. Perception, 28(10), 1217-1226.

Maurer, D., Le Grand, R., \& Mondloch, C. J. (2002). The many faces of configural processing. Trends in Cognitive Sciences, 6(6), 255-260.

Maurer, D., O'Craven, K. M., Le Grand, R., Mondloch, C. J., Springer, M. V., Lewis, T. L., et al. (2007). Neural correlates of processing facial identity based on features versus their spacing. Neuropsychologia, 45(7), 1438-1451.

Mazard, A., Schiltz, C., \& Rossion, B. (2006). Recovery from adaptation to facial identity is larger for upright than inverted faces in the human occipito-temporal cortex. Neuropsychologia, 44(6), 912-922.

McKone, E., Kanwisher, N., \& Duchaine, B. C. (2007). Can generic expertise explain special processing for faces? Trends in Cognitive Sciences, 11(1), 8-15.

Mondloch, C. J., Le Grand, R., \& Maurer, D. (2002). Configural face processing develops more slowly than featural face processing. Perception, 31(5), 553-566.

Murray, J. E., Yong, E., \& Rhodes, G. (2000). Revisiting the perception of upside-down faces. Psychological Science, 11(6), 492-496.

Ogawa, S., Lee, T. M., Kay, A. R., \& Tank, D. W. (1990). Brain magnetic resonance imaging with contrast dependent on blood oxygenation. Proceedings of the National Academy of Sciences USA, 87(24), 9868-9872.

Reed, C. L., Stone, V. E., Bozova, S., \& Tanaka, J. (2003). The body-inversion effect. Psychological Science, 14(4), 302-308.

Rhodes, G. (1988). Looking at faces: First-order and second-order features as determinants of facial appearance. Perception, 17(1), 43-63.

Rossion, B., Dricot, L., Zoontjes, R., Volder, A.-D., Bodart, J.-M., Crommelinck, M., et al. (2000). Hemispheric asymmetries for whole-based and part-based face processing in the human fusiform gyrus. Journal of Cognitive Neuroscience, 12, 793-802.

Rossion, B., \& Gauthier, I. (2002). How does the brain process upright and inverted faces? Behavioral and Cognitive Neuroscience Reviews, 1(1), 63-75.

Rotshtein, P., Geng, J. J., Driver, J., \& Dolan, R. J. (2007). Role of features and second-order spatial relations in face discrimination, face recognition, and individual face skills: Behavioral and functional magnetic resonance imaging data. Journal of Cognitive Neuroscience, 19(9), 1435-1452.

Rotshtein, P., Henson, R. N., Treves, A., Driver, J., \& Dolan, R. J. (2005). Morphing Marilyn into Maggie dissociates physical and identity face representations in the brain. Nature Neuroscience, 8(1), 107-113.

Sayres, R., \& Grill-Spector, K. (2006). Object-selective cortex exhibits performance-independent repetition suppression. Journal of Neurophysiology, 95, 995-1007. 


\title{
Copyright (C) The British Psychological Society
}

\author{
Reproduction in any form (including the internet) is prohibited without prior permission from the Society
}

Schiltz, C., \& Rossion, B. (2006). Faces are represented holistically in the human occipito-temporal cortex. Neuroimage, 32(3), 1385-1394.

Schwarzlose, R. F., Baker, C. I., \& Kanwisher, N. (2005). Separate face and body selectivity on the fusiform gyrus. Journal of Neuroscience, 25(47), 11055-11059.

Sergent, J. (1984). An investigation into component and configural processes underlying face perception. British Journal of Psychology, 75(Pt 2), 221-242.

Sergent, J., Ohta, S., \& MacDonald, B. (1992). Functional neuroanatomy of face and object processing. A positron emission tomography study. Brain, 11(Pt 1), 15-36.

Sergent, J., \& Signoret, J. -L. (1992). Varieties of functional deficits in prosopagnosia. Cerebral Cortex, 2, 375-388.

Sergent, J., \& Villemure, J. G. (1989). Prosopagnosia in a right hemispherectomized patient. Brain, 112 (Pt 4), 975-995.

Shi, J., Samal, A., \& Marx, D. (2006). How effective are landmarks and their geometry for face recognition? Computer Vision and Image Understanding, 102, 117-133.

Talairach, G., \& Tournoux, P. (1988). Co-planar stereotaxic atlas of the human brain. New York: Thieme.

Tanaka, J. W., \& Farah, M. J. (1993). Parts and wholes in face recognition. Quarterly Journal of Experimental Psychology A, 46(2), 225-245.

Valentine, T. (1988). Upside-down faces: A review of the effect of inversion upon face recognition. British Journal of Psychology, 79(Pt 4), 471-491.

Yi, D. J., Kelley, T. A., Marois, R., \& Chun, M. M. (2006). Attentional modulation of repetition attenuation is anatomically dissociable for scenes and faces. Brain Research, 1080(1), 53-62.

Yin, R. K. (1969). Looking at upside-down faces. Journal of Experimental Psychology, 81, 41-145.

Young, A. W., Hellawell, D., \& Hay, D. C. (1987). Configurational information in face perception. Perception, 16(6), 747-759.

Yovel, G., \& Kanwisher, N. (2004). Face perception: Domain specific, not process specific. Neuron, 44(5), 889-898.

Yovel, G., \& Kanwisher, N. (2005). The neural basis of the behavioral face-inversion effect. Current Biology, 15(24), 2256-2262.

Received 26 July 2007; revised version received I 3 February 2008 